\title{
Melatonin modifies basal and stimulated insulin secretion via NADPH oxidase
}

\author{
Daniel Simões', Patrícia Riva', Rodrigo Antonio Peliciari-Garcia1,2, \\ Vinicius Fernandes Cruzat', Maria Fernanda Graciano', Ana Claudia Munhoz', \\ Marco Taneda', José Cipolla-Neto' ${ }^{1}$ and Angelo Rafael Carpinelli ${ }^{1}$ \\ 'Department of Physiology and Biophysics, Institute of Biomedical Sciences-I, University of São Paulo, \\ São Paulo, Brazil \\ 2Department of Biological Sciences, Laboratory of Biosystems, Federal University of São Paulo, Diadema, \\ São Paulo, Brazil
}

Correspondence should be addressed to $D$ Simões

Email

simoes@icb.usp.br

\begin{abstract}
Melatonin is a hormone synthesized in the pineal gland, which modulates several functions within the organism, including the synchronization of glucose metabolism and glucosestimulated insulin secretion (GSIS). Melatonin can mediate different signaling pathways in pancreatic islets through two membrane receptors and via antioxidant or pro-oxidant enzymes modulation. NADPH oxidase (NOX) is a pro-oxidant enzyme responsible for the production of the reactive oxygen specie (ROS) superoxide, generated from molecular oxygen. In pancreatic islets, NOX-derived ROS can modulate glucose metabolism and regulate insulin secretion. Considering the roles of both melatonin and NOX in islets, the aim of this study was to evaluate the association of NOX and ROS production on glucose metabolism, basal and GSIS in pinealectomized rats (PINX) and in melatonin-treated isolated pancreatic islets. Our results showed that ROS content derived from NOX activity was increased in PINX at baseline $(2.8 \mathrm{mM}$ glucose), which was followed by a reduction in glucose metabolism and basal insulin secretion in this group. Under $16.7 \mathrm{mM}$ glucose, an increase in both glucose metabolism and GSIS was observed in PINX islets, without changes in ROS content. In isolated pancreatic islets from control animals incubated with $2.8 \mathrm{mM}$ glucose, melatonin treatment reduced ROS content, whereas in $16.7 \mathrm{mM}$ glucose, melatonin reduced ROS and GSIS. In conclusion, our results demonstrate that both basal and stimulated insulin secretion can be regulated by melatonin through the maintenance of ROS homeostasis in pancreatic islets.
\end{abstract}

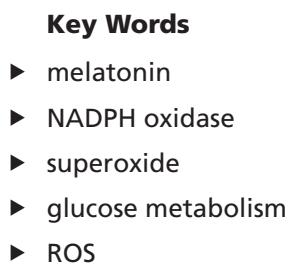

Journal of Endocrinology (2016) 231, 235-244

\section{Introduction}

Melatonin (N-acetyl-5-methoxytryptamine) is a hormone synthesized and released by the pineal gland at night, acting as a neuroendocrine transducer, regulating the day/ night cycle. Many physiological processes and functions are modulated by melatonin, including sleep-wake cycle synchronization, organismal and cellular metabolism as well as the activity of the reproductive axis (Bartness \& Goldman 1989). Melatonin receptors on the cell membrane, identified as MT1 and MT2 (Dubocovich 1995), belong to the superfamily of G-protein-coupled receptors

Published by Bioscientifica Ltd. 
and are expressed in several tissues (Bartness \& Goldman 1989), including pancreatic islets (Mühlbauer \& Peschke 2007). The second messenger signals recruited by these receptors modulate several intracellular mechanisms, altering the activities of adenylate cyclase, guanylate cyclase, phospholipases $\mathrm{C}$ and $\mathrm{A} 2$, and potassium and calcium channels (Morgan et al. 1995, Barrett et al. 1996, Hardeland 2009).

Melatonin, which is a highly diffusible hormone, may bind to the cell nucleus and has been shown to be a powerful antioxidant for biological systems. Acting as a scavenger of reactive oxygen and nitrogen species (ROS and RNS, respectively) (Reiter et al. 2008), melatonin can also inhibit some pro-oxidant enzymes, such as the NADPH oxidase (Zhou et al. 2008) and stimulate the expression of antioxidant enzymes, including glutathione peroxidase (GpX), catalase (CAT) and superoxide dismutase (SOD) (Reiter et al. 2008). Importantly, in pancreatic islets, melatonin has been considered a master regulator of ROS production (Ebelt et al. 2000), supporting a ROS-driven role for this hormone in islet function.

Although some studies described inhibitory or stimulatory effect of melatonin in the pancreas (Peschke $\&$ Peschke 1998), there are consistent scientific evidences supporting that melatonin inhibits insulin secretion in islets (Peschke et al. 2000) and clonal beta cell lines (Mühlbauer \& Peschke 2007). Picinato and coworkers (2002a) demonstrated that melatonin can inhibit glucose-stimulated insulin secretion (GSIS) through the MT1 receptor and its downstream signaling pathway (cAMP/PKA) in pancreatic islets (Picinato et al. 2002a). Studies also showed that insulin secretion can be inhibited by melatonin through MT2 receptor (Stumpf et al. 2008, 2009).

Data from our group demonstrate that ROS production through NADPH oxidase (NOX) complex (Rebelato et al. 2012, Graciano et al. 2013) has a significant role in the process of insulin secretion, negatively regulating GSIS in pancreatic islets and modulating glucose metabolism (Morgan et al. 2009, Rebelato et al. 2011). Briefly, NOX consists of two membrane-bound subunits, gp91phox and p22phox, which form the flavocytochrome $b_{558}$ enzymatic core. Upon activation, this complex associates with the cytosolic subunits p47phox, p67phox, p40phox and the small GTPase Rac1 (Babior 1999). Recruitment of the cytosolic components to the membrane-bound subunits is critical for NOX activity (Miyano \& Sumimoto 2007).

Therefore, considering the effects of melatonin on insulin secretion and its antioxidant properties, as well as the role of NADPH oxidase in islet ROS production, the aim of this study was to investigate the relationship between melatonin and NOX-derived ROS involved in the process of insulin secretion and pancreatic islets function.

\section{Material and methods}

\section{Ethics statement}

All experiments were performed under the guidelines of the Brazilian College for Animal Experimentation (COBEA) and the guidelines of the Animal Experimental Committee of the Institute of Biomedical Sciences, University of São Paulo.

\section{Reagents}

The reagents for sodium dodecyl sulfate-polyacrylamide gel electrophoresis (SDS-PAGE) and immunoblotting were obtained from Bio-Rad. Tris, EDTA, PMSF, aprotinin, dithiothreitol (DTT), Tween 20, Triton X-100, glycerol and collagenase were purchased from Sigma-Aldrich. Hydroethidine was obtained from Molecular Probes. The antibodies anti-p47phox and anti-gp91phox were obtained from Upstate Biotechnology (Upstate Biotechnology, Temecula, CA, USA), and anti- $\alpha$-tubulin was purchased from Invitrogen. The enhanced chemiluminescence reagent kit (ECL) was obtained from GE Healthcare. VAS2870, a specific inhibitor of NO, was obtained from Enzo Life Science (New York, EUA).

\section{Animals}

Male Wistar rats (200-250g) were kept on a $12 \mathrm{~h}$ light:12h darkness (LD) cycle (lights on at 07:00h) in a temperature controlled room $\left(23 \pm 2^{\circ} \mathrm{C}\right)$ and had access to food and water ad libitum. Animals were assigned to two experimental groups: control (CTL) and pinealectomized (PINX).

\section{Surgical procedures}

Rats were subjected to pinealectomy (PINX) or SHAM (control) surgery as described previously (Hoffman \& Reiter 1965). All the experiments were performed after 45 days of pinealectomy, during which melatonin levels were absent $(0 \mathrm{pg} / \mathrm{mL}$ for PINX group $n=10$ and $22 \pm 3 \mathrm{pg} / \mathrm{mL}$ for the control group $n=10$ ), according to blood sample assays using ultrahigh-performance liquid

Published by Bioscientifica Ltd. 
chromatography (Dionex UHPLC Ultimate 3000) with electrochemical detection (ESA Coulochem III) and an autosampler (WPS-3000TSL with sample thermosetting) running Chromeleon software. These results confirmed that the PINX method completely removes melatonin from the circulation. In addition, PINX was confirmed post-mortem by careful visual inspection. Our group already demonstrated the efficacy of PINX procedure in previous publications (Agez et al. 2009, Fisher \& Sugden 2010, Jaworek et al. 2010, Nogueira et al. 2011).

\section{Pancreatic islets isolation}

Pancreatic islets were isolated using collagenase digestion method, as described previously by Lacy and Kostianovsky (1967). Briefly, after distension via pancreatic duct injection with collagenase $(0.68 \mathrm{mg} / \mathrm{mL})$, pancreas was removed and digested in a shaking water bath at $37^{\circ} \mathrm{C}$. Pancreatic islets were isolated from PINX and sham-operated animals to confirm the chronic effects of the absence of melatonin. In addition, islets were also obtained from control animals to determine the acute in vitro effects of melatonin.

\section{Static insulin secretion}

Groups of 5 islets were preincubated at $37^{\circ} \mathrm{C}$ for $30 \mathrm{~min}$ in $0.5 \mathrm{~mL}$ Krebs-Henseleit $(\mathrm{KH})$ with $0.2 \%$ bovine serum albumin (BSA) in $5.6 \mathrm{mM}$ glucose and incubated for $1 \mathrm{~h}$ in $\mathrm{KH}$ with $0.2 \% \mathrm{BSA}$ in different concentrations of glucose (2.8 and $16.7 \mathrm{mM})$. At the end of the experiment, the medium was collected, and insulin was measured by radioimmunoassay (RIA) using human insulin as a standard. For total insulin content, islets in each well were disrupted in $500 \mu \mathrm{L}$ acid ethanol solution (52 ethanol: 17 water; 1 chloridic acid) and sonicated ( 3 pulses of $5 \mathrm{~s})$. Insulin was measured by RIA. Insulin secretion was calculated as the insulin secreted per total insulin content in the islets. Radioactive insulin was purchased from PerkinElmer.

\section{Analysis of superoxide content in pancreatic islets}

Superoxide production was determined by dihydroethidium (DHE) fluorescence evaluation. The reaction between anion superoxide and DHE results in the formation of an oxidized product that intercalates into DNA, staining a red fluorescence in the nucleus (Zhao et al. 2003).
Groups of 20 islets were preincubated at $37^{\circ} \mathrm{C}$ for $30 \mathrm{~min}$ in $0.5 \mathrm{~mL} \mathrm{KH}$ with $0.2 \% \mathrm{BSA}$ in $5.6 \mathrm{mM}$ glucose and incubated for $1 \mathrm{~h}$ in $\mathrm{KH}$ with $0.2 \% \mathrm{BSA}$ in the presence of 2.8 and $16.7 \mathrm{mM}$ glucose. After incubation, DHE was added to a final concentration of $50 \mu \mathrm{M}$. Samples, protected from light, were then incubated for an additional $20 \mathrm{~min}$ at room temperature. Islets were disrupted with trypsin and gentle pipetting and resuspended in $200 \mu \mathrm{L}$ of RPMI- 1640 medium and placed in a 96-well plate for analysis in flow cytometer (Guava EasyCyte, Millipore). Fluorescence was assessed, and averages were normalized to glucose $2.8 \mathrm{mM}$ averages. Data were expressed as mean fluorescence intensity (MFI).

\section{Measurement of $\left[{ }^{14} \mathrm{C}\right]$-glucose decarboxylation}

Groups of islets were incubated in $1.2 \mathrm{~mL}$ of $\mathrm{KH}$ buffer containing BSA $0.2 \%$ at $37^{\circ} \mathrm{C}$ in glass vials containing a filter paper and $400 \mu \mathrm{L}$ of phenylethylamine, diluted $1: 1 \mathrm{v} / \mathrm{v}$ in methanol, in a separate compartment. The incubation buffer contained $36 \mu \mathrm{Ci} / \mathrm{mmol}$ of $\left[\mathrm{U}^{-14} \mathrm{C}\right]-$ glucose. In the experiments performed to measure $\left[\mathrm{U}-{ }^{14} \mathrm{C}\right]$-glucose oxidation, islets were incubated in the presence of 2.8 and $16.7 \mathrm{mM}$ glucose for $1 \mathrm{~h}$. The incubation stopped by the addition of $400 \mu \mathrm{L} \mathrm{HCL}$ $(10 \mathrm{~mol} / \mathrm{L})$, and the vials were shaken for additional $90 \mathrm{~min}$. The filter paper with phenylethylamine was transferred to a plastic tube with $1.8 \mathrm{~mL}$ of biodegradable scintillation liquid (Amersham Pharmacia, Uppsala, Sweden), and the adsorbed ${ }^{14} \mathrm{CO}_{2}$ was measured using a scintillation counter (Beckman-LS 5000TD, Beckman Instruments, Fullerton, CA, USA).

\section{Western blot analysis}

Groups of 350 islets were resuspended in $80 \mu \mathrm{L}$ extraction buffer $(100 \mathrm{mM}$ Tris, $1 \%$ Triton X-100, $0.01 \mathrm{mg} / \mathrm{mL}$ aprotinin, $2 \mathrm{mM}$ PMSF, $10 \mathrm{mM} \mathrm{Na} \mathrm{VO}_{4}, 10 \mathrm{mM} \mathrm{NaF}$, $10 \mathrm{mM} \mathrm{Na}{ }_{4} \mathrm{P}_{2} \mathrm{O}_{7}$ and $10 \mathrm{mM}$ EDTA). The samples were boiled for $5 \mathrm{~min}$ and centrifuged for $20 \mathrm{~min}$ at $4^{\circ} \mathrm{C}$ $(10,000 \mathrm{~g})$. The protein content of the supernatant was determined by the Bradford method (1976). For immunoprecipitation (IP), pancreatic islet extracts were centrifuged for $20 \mathrm{~min}$ at $4^{\circ} \mathrm{C}(12,000 \mathrm{~g})$. The supernatant (3 $\mathrm{mg}$ of protein) was used for IP with anti-p47phox and protein A-Sepharose $6 \mathrm{MB}$ before Laemmli sample buffer containing $100 \mathrm{mM}$ dithiothreitol. After running gel electrophoresis (10\% gel) and transferring to PVDF membrane, expression of the subunits of NADPH oxidase

Published by Bioscientifica Ltd. 
Table 1 Rabbit and mouse antibodies and respective dilutions.

\begin{tabular}{|c|c|c|}
\hline Antibody & Animal origin & Dilution \\
\hline $\begin{array}{l}\text { Polyclonal anti-p47PHOx } \\
\text { (Upstate Cell Signalling Solutions) }\end{array}$ & Rabbit & $1: 500$ \\
\hline $\begin{array}{l}\text { Polyclonal anti-gp91PHOx } \\
\text { (Upstate Cell Signalling Solutions) }\end{array}$ & Rabbit & 1:1000 \\
\hline Monoclonal anti- $\alpha$ Tubulin (Zymed) & Mouse & $1: 2000$ \\
\hline $\begin{array}{l}\text { Rabbit anti-IgG/peroxidase } \\
\text { (Amersham) }\end{array}$ & Mouse & $1: 10,000$ \\
\hline $\begin{array}{l}\text { Mouse anti-lgG/peroxidase } \\
\text { (Amersham) }\end{array}$ & Rabbit & $1: 10,000$ \\
\hline
\end{tabular}

was assessed using the antibodies described in Table 1. The enhanced chemiluminescence reagents - ECL (GE Healthcare) were used, and the membrane was exposed to photographic film or Image Quant apparatus, GE Healthcare (GE Healthcare AS). The intensity of the bands was quantified by optical densitometry using ImageJ software (Wayne Rasbond, NIH, Bethesda, MD, USA). Quantification of protein expression was normalized by protein $\alpha$-tubulin.

\section{RNA isolation}

Total RNA was isolated from fresh islets, using TRIzol (Life Technologies) according to the manufacturer's instructions. RNA concentration was determined by spectrophotometry using NanoDrop2000, whereas its integrity was evaluated in a $2 \%(\mathrm{w} / \mathrm{v})$ agarose gel containing ethidium bromide.

\section{Real time-PCR}

Total RNA (3 $\mu \mathrm{g})$ obtained from isolated pancreatic islets was reverse transcribed to cDNA. Glucose transporter 2
(Glut2), glucokinase (Gck), superoxide dismutase (Sod1), catalase (Cat) and glutathione peroxidase (Gpx) mRNA expressions were evaluated by real-time PCR using ROTOR-GENE 3000 equipment (Corbett Research, Mortlake, Australia) and SYBR GREEN (Invitrogen) as fluorescent dye. Gene expression was evaluated by the 2(-Delta CT) method (Livak \& Schmittgen 2001) using the ribosomal protein L37 $\alpha$ (Rpl37a) or hypoxanthine guanine phosphoribosyl transferase (Hprt) gene expression as an inner control. The Ct value is the calculated cycle number where the fluorescence signal was emitted significantly above the background levels. The sequences of the used primers, manufactured by Integrated DNA Technologies (Coralville, IA, USA), are described in Table 2.

\section{Statistical analysis}

Results are presented as mean \pm S.E.M. Two-way ANOVA, followed by Bonferroni's post hoc test was applied. Statistical analyses were also performed using the unpaired Student's $t$-test when appropriate, and $P<0.05$ was considered to be statistically significant. GraphPad Prism software was used in the data analyses (GraphPad Software v4.03).

\section{Results}

\section{Pinealectomy results in an increase of ROS content in isolated pancreatic islets}

ROS generation was first evaluated in isolated pancreatic islets from control (CTL) and pinealectomized (PINX) rats. All experiments were performed using low $(2.8 \mathrm{mM})$

Table 2 Primer sequences for rat qPCR assays.

\begin{tabular}{|c|c|c|c|c|}
\hline Gene/GenBank accession \# & \multicolumn{2}{|l|}{ Primer sequence } & Product length $(b p)$ & Temperature $\left({ }^{\circ} \mathrm{C}\right)$ \\
\hline \multirow[t]{2}{*}{ rSIc2a2/NM_012879.2 } & \multicolumn{2}{|c|}{ 5'-CAGGGTGAAGACCAGGACCA-3' } & 80 & 58.1 \\
\hline & \multicolumn{2}{|c|}{ 5'-CCTCTGCTTCCAGTACATTGC-3' } & & 61.0 \\
\hline \multirow[t]{2}{*}{ rGck/NM_001270849.1 } & \multicolumn{2}{|c|}{ 5'-CCGTTTCGTGTCACAAGTGGA-3' } & 156 & 60.7 \\
\hline & \multicolumn{2}{|c|}{ 5'-ATATGTGCTCCGCAG-3' } & & 58.0 \\
\hline \multirow[t]{2}{*}{ rSod1/NM_017050.1 } & \multicolumn{2}{|c|}{ 5'-CCGGTGCAGGGCGTC-3' } & 74 & 59.2 \\
\hline & \multicolumn{2}{|c|}{ 5'-TCCTGTAATCTGTCCTGACACCA-3' } & & 58.2 \\
\hline \multirow[t]{2}{*}{ rCat/NM_012520.1 } & \multicolumn{2}{|c|}{ 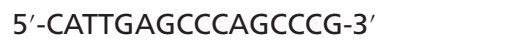 } & 64 & 52.2 \\
\hline & \multicolumn{2}{|c|}{ 5'-GGCGGTGAGTGTCTGGGTAA-3' } & & 59.6 \\
\hline \multirow[t]{2}{*}{ rGpx/NM_030826.3 } & \multirow{2}{*}{\multicolumn{2}{|c|}{ 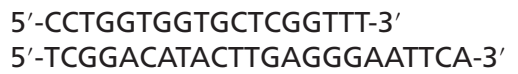 }} & 90 & 58.1 \\
\hline & & & & 59.4 \\
\hline \multirow[t]{2}{*}{ rRp/37a/NM_001108801 } & \multicolumn{2}{|c|}{ 5'-TTGAAATCAGCCAGCACGC-3' } & 74 & 59.5 \\
\hline & \multicolumn{2}{|c|}{ 5'-TGCCAACGCCTCGTCTCT-3' } & & 59.1 \\
\hline \multirow[t]{2}{*}{ rCyba/NM_024160.1 } & \multicolumn{2}{|c|}{ 5'-GAGGTCCGCAAGAAGCCAAG-3' } & 120 & 56.2 \\
\hline & \multicolumn{2}{|c|}{ 5'-GAAACTCAAGCAGGAGCCACTG-3' } & & 55.5 \\
\hline \multirow[t]{2}{*}{ rHprt/S79292.1 } & \multicolumn{2}{|c|}{ 5'-GCTGAAGATTTGGAAAAGGTGT-3' } & 112 & 54 \\
\hline & \multicolumn{2}{|c|}{ 5'-ACAGAGGGCCACAATGTGAT-3' } & & 54 \\
\hline
\end{tabular}



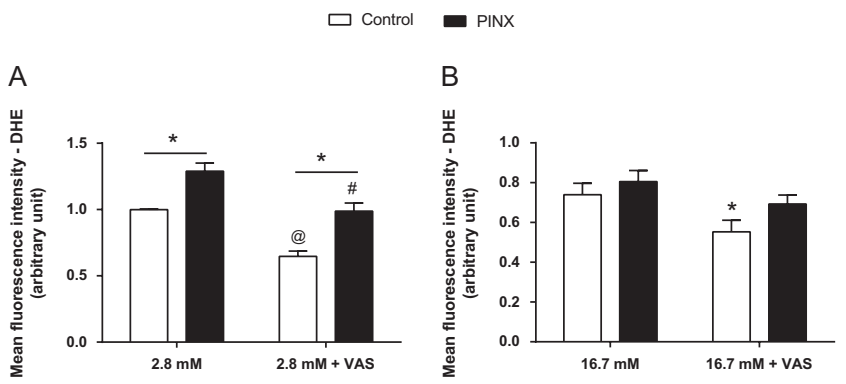

Figure 1

PINX effect on ROS content. Mean fluorescence intensity by dihydroethidium (DHE) in isolated pancreatic islets after $60 \mathrm{~min}$ of incubation with $2.8 \mathrm{mM}(\mathrm{A})$ and $16.7 \mathrm{mM}$ (B) glucose in the presence or absence of $20 \mu \mathrm{M}$ VAS2870 (VAS), an inhibitor of NADPH oxidase. Results are presented as mean \pm s.E.M. $(n=8)$. Two-way ANOVA, Bonferroni's post hoc test. (A) $* P<0.05 ; \otimes P<0.05$ vs CTL $2.8 \mathrm{mM}$; $\# P<0.05$ vs $2.8 \mathrm{mM}$ PINX $2.8 \mathrm{mM}$; (B) ${ }^{*} P<0.05$ vs $16.7 \mathrm{CTL}$. CTL, control; PINX, pinealectomy.

and high $(16.7 \mathrm{mM})$ glucose concentrations to explore the minimum and maximum responses of pancreatic islets to glucose. An increase of $29 \%$ in intracellular ROS content after $1 \mathrm{~h}$ of incubation with $2.8 \mathrm{mM}$ glucose was observed in PINX rats compared with CTL (Fig. 1A). To verify whether NOX was the source of ROS in our model, a well-known NOX inhibitor, VAS2870 (Wind et al. 2010, Wingler et al. 2011, Kahles \& Brandes 2012, Altenhofer et al. 2015), was used. In low glucose, a reduction in ROS content was observed in both CTL and PINX groups (36 and $24.4 \%$, respectively) after VAS2870 treatment, but PINX-derived islets still presented higher ROS content than CTL islets (Fig. 1A). Under high glucose, there was no significant difference between groups, despite a $25.2 \%$ reduction in ROS levels in CTL group after treatment with NOX inhibitor (Fig. 1B).

\section{Pinealectomy increases NADPH oxidase assembly}

The effect of PINX on the expression of NOX components, p47phox and gp91phox, was investigated in isolated pancreatic islets by Western blot. The analysis showed no changes in total protein content of these subunits (Fig. 2A and B). Association of the cytosolic NOX subunit,
A

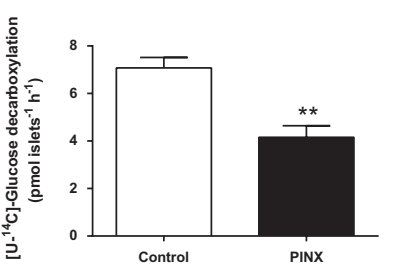

C

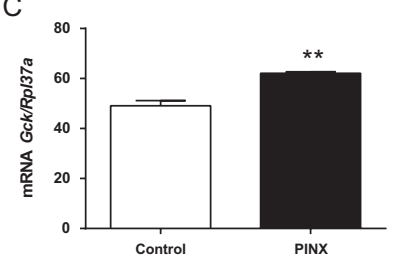

B

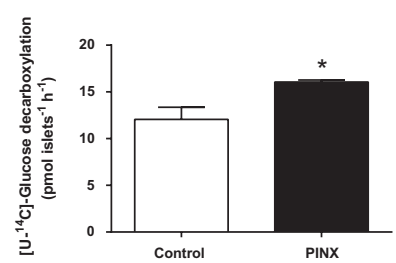

D

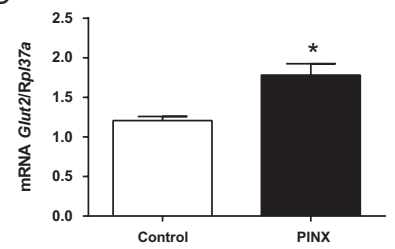

Figure 3

PINX effect on $\left[{ }^{14} \mathrm{C}\right]$-glucose decarboxylation and mRNA expression of Glut2 and Gck in isolated pancreatic islets. The islets were incubated for $60 \mathrm{~min}$ in $2.8 \mathrm{mM}(\mathrm{A})$ or $16.7 \mathrm{mM}$ (B) glucose. Total glucokinase mRNA (Gck) expression (C) and Glut2 mRNA expression (D) were evaluated in islets obtained from pinealectomy (PINX) and control (CTL) animals after sacrifice. Results are presented as mean \pm S.E.M. $(n=5)$. Two-way ANOVA, Bonferroni's post hoc test. ${ }^{*} P<0.05, * * P<0.01$.

p47phox, to the membrane-bound gp91phox is a key step in the activation of the oxidase and subsequent superoxide generation (Bedard \& Krause 2007). We, therefore, assessed this association by immunoprecipitation with anti-p47phox followed by immunoblotting against gp91 phox in $2.8 \mathrm{mM}$ glucose. Data revealed an $18 \%$ increase in gp91phox-p47phox association in the PINX group compared with CTL animals, indicative of increased enzymatic activation (Fig. 2C).

\section{Measurement of [ $\left.{ }^{14} \mathrm{C}\right]$-glucose decarboxylation and Gsk and Glut2 mRNA expression in PINX animals}

In an attempt to estimate the metabolic flux by the glycolytic pathway, which can be linked to the insulin secretion process, $\left[{ }^{14} \mathrm{C}\right]$ glucose decarboxylation was assessed in PINX and CTL rats. Under $2.8 \mathrm{mM}$ glucose, a reduction of $41.4 \%$ in glucose decarboxylation was observed in PINX group (Fig. 3A). However, a high

A

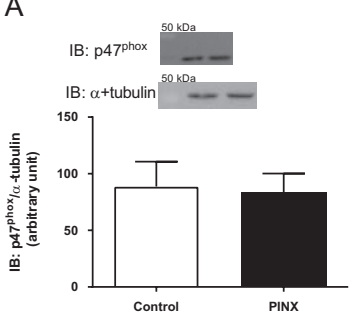

http://joe.endocrinology-journals.org DOI: 10.1530/JOE-16-0259
B

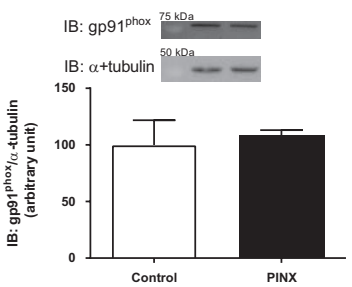

C

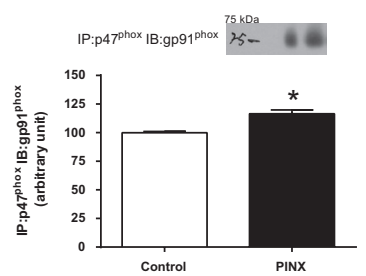

Figure 2

PINX effect on protein expression of $p 47^{\text {phox }}$ and gp91 phox and NADPH oxidase activity in isolated pancreatic islets. (A) p47phox protein expression, (B) gp91phox protein expression and (C) immunoprecipitated IP: p47phox IB: gp91 phox after $30 \mathrm{~min}$ of incubation with $2.8 \mathrm{mM}$ glucose. Results are presented as mean \pm S.E.M. $(n=3)$. Student's $t$-test * $P<0.05, C T L$, control; PINX, pinealectomy. 

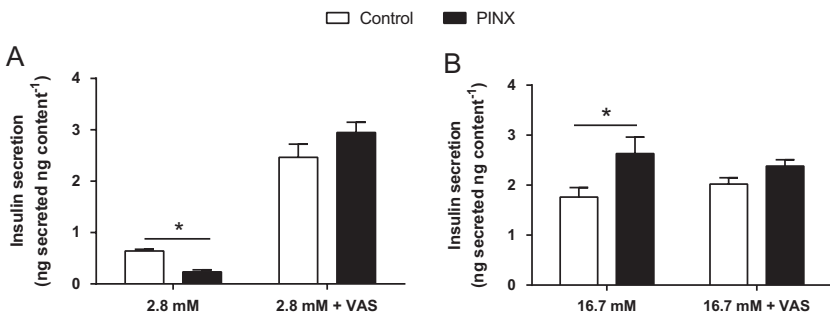

Figure 4

PINX effect on static insulin secretion in pancreatic islets. Pancreatic islets were isolated and incubated for $60 \mathrm{~min}$ with $2.8 \mathrm{mM}(\mathrm{A})$ and $16.7 \mathrm{mM}(\mathrm{B})$ glucose and $20 \mu \mathrm{M}$ VAS2870 (VAS), an inhibitor of NADPH oxidase. Results are presented as mean \pm S.E.M. $(n=5)$. Two-way ANOVA, Bonferroni's post hoc test. ${ }^{*} P<0.05$. CTL, control; PINX, pinealectomy.

glucose concentration raised the glucose decarboxylation in the PINX group by $33.3 \%$ compared to CTL (Fig. 3B). Furthermore, it was observed that PINX induced a greater expression of two essential genes involved in glucose metabolism, Gck and Glut2 (Fig. 3C and D).

\section{Pinealectomy dysregulates basal and glucose-stimulated insulin secretion (GSIS)}

To estimate the functionality of pancreatic islets under the absence of melatonin, basal and glucose-stimulated insulin secretion assays were performed. In PINX group, a decrease of $63 \%$ in insulin secretion was observed at $2.8 \mathrm{mM}$ glucose in comparison with CTL, and the inhibition of NOX by VAS2870 at this same basal condition promoted an increase in insulin secretion in both groups (Fig. 4A). Under $16.7 \mathrm{mM}$ glucose (stimulated condition), pinealectomy caused an increase of $49 \%$ in insulin compared with CTL. Inhibition of NOX by VAS2870 at this glucose concentration, however, had no effect on insulin secretion (Fig. 4B).

\section{Pinealectomy and antioxidant transcripts}

To test whether antioxidant enzymes were changed due to pinealectomy, mRNA expression of Sod1, Gpx and Catalase was assessed by qPCR on control and PINXisolated pancreatic islets. We observed a decrease in Sod1
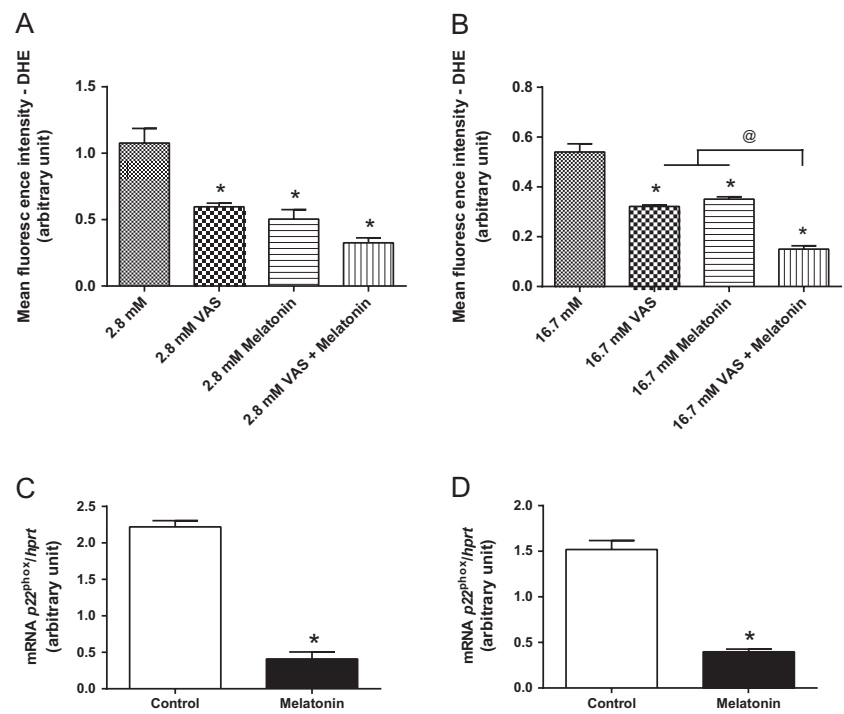

Figure 6

Melatonin effects on ROS content and p22 phox mRNA expression in islets obtained from control animals. Mean fluorescence intensity by dihydroethidium (DHE) in isolated pancreatic islets after $60 \mathrm{~min}$ of incubation with $2.8 \mathrm{mM}(\mathrm{A})$ and $16.7 \mathrm{mM}$ (B) glucose, $20 \mu \mathrm{M}$ VAS 2870 (VAS) an inhibitor of NADPH oxidase and $100 \eta \mathrm{M}$ melatonin. (C) p22 phox mRNA expression in $2.8 \mathrm{mM}$ and (D) p22phox in $16.7 \mathrm{mM}$ glucose and $100 \eta \mathrm{M}$ melatonin. Results are presented as mean \pm S.E.M. $(n=5)$. Two-way ANOVA, Bonferroni's post hoc test. (A) $* P<0.05$ (B) $* P<0.05$, ${ }^{\circledR} P<0.05$, (C) and (D) * $P<0.05$

(Fig. 5A) expression, but no differences in Gpx (Fig. 5B) and Catalase (Fig. 5C) gene expression were found between the two groups.

\section{Melatonin treatment decreases ROS content and p22 phox subunit mRNA expression in pancreatic islets}

Figure 6 shows the acute effect of melatonin treatment $(100 \eta \mathrm{M})$, NADPH oxidase inhibitor (VAS2870-20 $\mu \mathrm{M})$ and their combination on superoxide content in pancreatic islets obtained from control animals at different glucose concentrations (2.8 and $16.7 \mathrm{mM}$ ). Under $2.8 \mathrm{mM}$ of glucose, VAS2 870 decreased $46 \%$, melatonin $54 \%$ and the combination of melatonin and VAS2870 70\% compared with baseline (Fig. 6A). Under $16.7 \mathrm{mM}$ glucose, VAS2870, melatonin and the association of melatonin and VAS2870
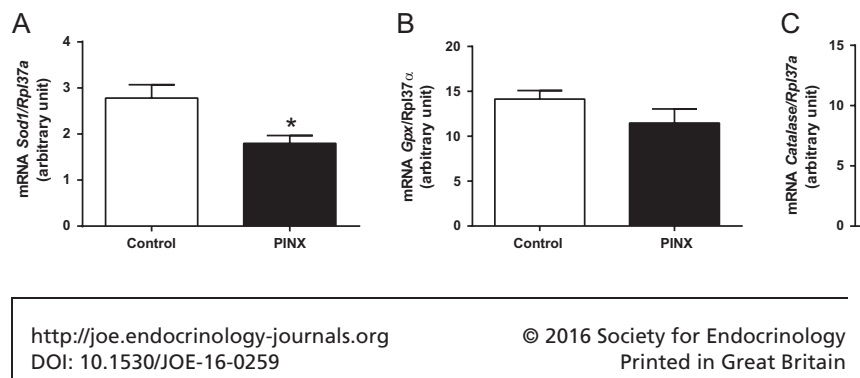

http://joe.endocrinology-journals.org DOI: $10.1530 / J O E-16-0259$
() 2016 Society for Endocrinology Printed in Great Britain
Figure 5

Analysis of mRNA expression of antioxidant enzymes in pancreatic islets. (A) Sod1, (B) Gpx and (C) Catalase gene expressions in islets obtained from pinealectomy (PINX) and control (CTL) animals after sacrifice. Results are presented as mean \pm S.E.M. normalized by the housekeeping gene $R p / 37 a(n=5)$.

Student's $t$-test, ${ }^{*} P<0.05$. 
A

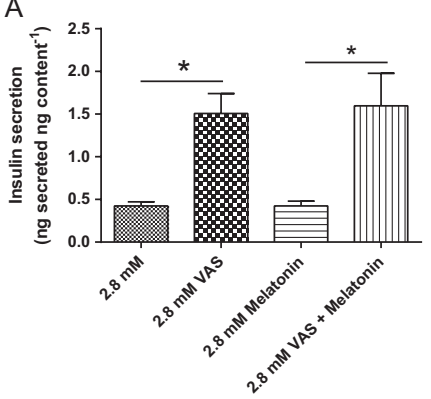

B

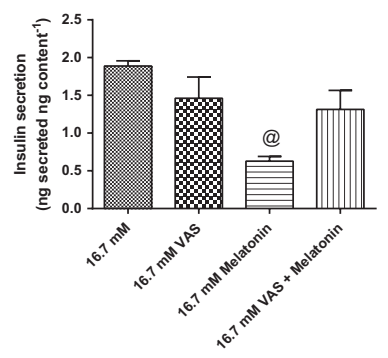

Figure 7

Melatonin effects on static insulin secretion in pancreatic islets. Pancreatic islets were isolated and incubated for $60 \mathrm{~min}$ with $2.8 \mathrm{mM}(A)$ and $16.7 \mathrm{mM}$ (B) glucose and $20 \mu \mathrm{M}$ VAS2870 (VAS), an inhibitor of NADPH oxidase and $100 \eta \mathrm{M}$ melatonin. Results are presented as mean \pm S.E.M. $(n=5)$. Two-way ANOVA, Bonferroni's post hoc test. (A) $* P<0.05$ vs $2.8 \mathrm{mM}$ CTL, (B) ${ }^{\circledR} P<0.05$ vs $16.7 \mathrm{mM}$.

induced a reduction of ROS content to 41, 36 and $73 \%$, respectively. We next evaluated the expression of p22phox mRNA, a subunit of NADPH oxidase, after supplementation with melatonin. The challenge with melatonin promoted a significant reduction of p22phox mRNA expression under 2.8 and $16.7 \mathrm{mM}$ glucose concentrations (Fig. 6C and D).

\section{Melatonin treatment does not change basal insulin secretion and reduces glucose-stimulated insulin secretion (GSIS)}

To verify the capacity of the pancreatic islets to secrete insulin after acute supplementation of melatonin, VAS2870 and the combination of melatonin and VAS2870, an insulin secretion assay was performed. The inhibition of NOX by VAS2870 induced a high insulin secretion at $2.8 \mathrm{mM}$ glucose compared with that at $2.8 \mathrm{mM}$ baseline, whereas melatonin treatment did not change the basal insulin secretion and the combination of VAS2870 and melatonin induced a greater insulin release at $2.8 \mathrm{mM}$ glucose (Fig. 7A). Under $16.7 \mathrm{mM}$ glucose, the challenge with melatonin promoted a significant reduction in glucose-stimulated insulin secretion. The VAS2870 group, as well as the combination of VAS2870 and melatonin, did not alter the insulin secretion at 16.7 mM glucose (Fig. 7B).

\section{Discussion}

The present work shows that NADPH oxidase-derived ROS oxidase plays a significant role in the regulation of basal and GSIS in isolated pancreatic islets, and melatonin is an important modulator of this mechanism.

The chronic absence of melatonin in PINX rats raised the levels of ROS in isolated islets under basal levels of glucose $(2.8 \mathrm{mM})$. This high ROS content was associated with an increased interaction of the cytosolic NOX subunit p47phox to the membrane-bound gp91phox, a key step in the activation of the oxidase system, and subsequent ROS generation. Islets treated with VAS2870 caused a reduction in ROS content at $2.8 \mathrm{mM}$ glucose, demonstrating that NOX possesses a high activity at low glucose levels (Munhoz et al. 2016). Previous works have also demonstrated that melatonin can directly regulate ROS generation and modulate pro-oxidant enzymes expression, such as the NADPH oxidase (Zhou et al. 2008).

Conversely, under high glucose exposure, inhibition of NOX did not reduce ROS levels in PINX animals. Melatonin can affect many systems in the cell, such as the mitochondrial metabolism (Ramis et al. 2015); hence, it is plausible that the absence of melatonin may induce ROS production not only through NOX but also through other oxidant sources, such as the mitochondria. However, it is important to consider that DHE is a specific probe for the detection of cytosolic ROS content (Zhao et al. 2003, Dikalov 2011), and previous publications have already shown that most of the ROS products generated after glucose stimulation are superoxide, which was confirmed using SOD linked to polyethylene glycol (PEG-SOD) (Graciano et al. 2013).

It was observed that under $2.8 \mathrm{mM}$ glucose, the increased ROS generation in PINX rats was accompanied by a significant decrease in glucose metabolism. In a study by Rebelato and coworkers (2010), low doses of hydrogen peroxide impaired glucose metabolism, as well as basal and GSIS (Rebelato et al. 2010). ROS are known to decrease the activity of both glyceraldehyde-3-phosphate dehydrogenase (GAPDH) (glycolytic pathway) (Lind et al. 1998) and aconitase (Bulteau et al. 2003) (Krebs cycle), thereby reducing the formation of $\left[\mathrm{U}^{14} \mathrm{CO}_{2}\right]$ under low glucose concentration. Our results with $\left[\mathrm{U}^{14} \mathrm{CO}_{2}\right]$ are consistent with these findings.

Under $16.7 \mathrm{mM}$ glucose, PINX group showed a higher glucose metabolism capacity than the controls, possibly because ROS can decrease GAPDH and aconitase activity and induce an increase in glucose metabolism, which was also observed by Picinato and coworkers (2002a). Also, PINX induced a higher mRNA expression of Glut2 and Gck, which are involved in the transport and phosphorylation of glucose inside the cell.

Published by Bioscientifica Ltd. 
Bazwinsky-Wutschke and coworkers (2014) observed that MT1/MT2 receptor knockdown increased the expression of Glut2 (Bazwinsky-Wutschke et al. 2014), possibly through the lower activation of the transcriptional factor CREB, which is also modulated by melatonin (Bazwinsky-Wutschke et al. 2012). Taken together, the defect of melatonin signaling can lead to an increase in Glut2 expression and contributes to increased glucose metabolism in PINX animals.

Under $2.8 \mathrm{mM}$ glucose concentration, the absence of melatonin induced an impairment of basal insulin secretion. Furthermore, a reduction in glucose metabolism and an increase in NOX-derived ROS were observed. The decrease of basal insulin secretion was entirely reversed by the NOX inhibitor VAS2870, indicating that NOXderived ROS can modulate basal insulin secretion. Under $16.7 \mathrm{mM}$ glucose, PINX presented an increase in glucosestimulated insulin secretion, which may be linked to the increased glucose metabolism and a decrease in ROS content. It has been shown that in high glucose, i.e., $16.7 \mathrm{mM}$, there is an increase of antioxidant enzymes activity, such as superoxide dismutase (SOD) (Oliveira et al. 1999), which can also contribute to decrease the ROS content. Due to the fact that the antioxidant defense system is probably in their optimal activation state under high glucose concentration, the presence of VAS2870 did not cause a significant change in ROS levels, as observed in basal condition (Oliveira et al. 1999, Munhoz et al. 2016).

Recent evidence shows that insulin secretion is inversely related to ROS concentration (Rebelato et al. 2011, Graciano et al. 2013). Under low glucose, high ROS content limits insulin secretion to basal levels (Munhoz et al. 2016). On the other hand, in high glucose concentration, such as $16.7 \mathrm{mM}$, ROS levels are reduced, promoting high insulin secretion (Rebelato et al. 2011). As melatonin can modulate ROS production (Reiter et al. 2008, Zhang \& Zhang 2014), it would be expected that its absence could dysregulate ROS content, as well as basal insulin secretion and GSIS. This is consistent with our current findings, which demonstrate that PINX modifies the relationship between ROS and insulin secretion at different glucose concentrations.

To investigate the acute effects of melatonin supplementation on ROS production and insulin secretion, we incubated isolated islets with $100 \eta \mathrm{M}$ of melatonin. Melatonin treatment was able to reduce ROS production in both 2.8 and $16.7 \mathrm{mM}$ glucose concentrations, possibly due its antioxidant properties
(Reiter et al. 2008) and the combination of melatonin and VAS2870 further inhibits ROS production. The challenge with melatonin also reduced the expression of the membrane-bound $\mathrm{p} 22^{\text {phox }}$ subunit in both glucose concentrations. The p22phox subunit is critical for NOX activity (Bedard \& Krause 2007), and its reduction can be associated with the observed low ROS production in our experiments.

Under $2.8 \mathrm{mM}$ glucose level, melatonin per se did not change basal insulin secretion, even when ROS content was reduced, showing that at least acutely, melatonin pleiotropic effects overwhelm the regulation promoted by ROS on control of insulin secretion (Peschke et al. 2000). In cell lines, such as INS-1E (Stumpf et al. 2008, 2009), and isolated pancreatic islets (Picinato et al. 2002b), melatonin may inhibit insulin secretion through MT1 and MT2 receptors, which modulate AMPc and GMPc, respectively. Activation of melatonin receptors reduces the level of these second messengers, which are necessary for the amplification of secretory response via PKA and PKG (Peschke et al. 2000, Stumpf et al. 2008, 2009). On the other hand, the reduction in ROS content, promoted by the inhibition of NOX, induced an increase in basal insulin secretion.

A similar response was found in $16.7 \mathrm{mM}$ glucose. Melatonin treatment reduced glucose-stimulated insulin secretion despite the reduction in intracellular ROS content. As mentioned previously, receptor-mediated melatonin effects also seem to override the modulation of insulin secretion by ROS in this condition. Under high glucose, VAS2870 treatment lowered ROS production, but did not promote additional insulin release, probably for the reason that cells were already on their maximum secretory capacity due to glucose stimulation (Rebelato et al. 2011).

As a whole, many studies have shown the relevance of intracellular ROS for GSIS regulation in pancreatic islets (Rebelato et al. 2011, Li et al. 2012). However, the underlying mechanisms of pancreatic $\beta$-cell function modulated by ROS are not fully understood. Here, we provided evidence that melatonin can modulate NADPH oxidase-derived ROS production, and through this pathway be an important regulator of glucose metabolism, basal insulin secretion and GSIS.

\section{Declaration of interest}

The authors declare that there is no conflict of interest that could be perceived as prejudicing the impartiality of the research reported.
() 2016 Society for Endocrinology Printed in Great Britain
Published by Bioscientifica Ltd 


\section{Funding}

This research was supported by Fundação de Amparo à Pesquisa do Estado de São Paulo (FAPESP) (2013/08769-1). Other scholarships were provided by the Brazilian National Council for Scientific and Technological Development (CNPQ) and Coordenação de Aperfeiçoamento de Pessoal de Nível Superior (CAPES).

\section{Acknowledgements}

The authors are indebted to M S Rocha and J Scialfa for her excellent technical assistance.

\section{References}

Agez L, Laurent V, Guerrero HY, Pévet P, Masson-Pévet M \& Gauer F 2009 Endogenous melatonin provides an effective circadian message to both the suprachiasmatic nuclei and the pars tuberalis of the rat. Journal of Pineal Research 46 95-105. (doi:10.1111/j.1600079X.2008.00636.x)

Altenhofer S, Radermacher KA, Kleikers PW, Wingler K \& Schmidt HH 2015 Evolution of NADPH oxidase inhibitors: selectivity and mechanisms for target engagement. Antioxidants and Redox Signaling 23 406-427. (doi:10.1089/ars.2013.5814)

Babior BM 1999 NADPH oxidase: an update. Blood 93 1464-1476. Barrett P, MacLean A, Davidson G \& Morgan PJ 1996 Regulation of the Mel 1a melatonin receptor mRNA and protein levels in the ovine pars tuberalis: evidence for a cyclic adenosine $3^{\prime}, 5^{\prime}$-monophosphateindependent Mel 1a receptor coupling and an autoregulatory mechanism of expression. Molecular Endocrinology 10 892-902. (doi:10.1210/mend.10.7.8813729)

Bartness TJ \& Goldman BD 1989 Mammalian pineal melatonin: a clock for all seasons. Experientia 45 939-945. (doi:10.1007/BF01953051)

Bazwinsky-Wutschke I, Wolgast S, Mühlbauer E, Albrecht E \& Peschke E 2012 Phosphorylation of cyclic AMP-response element-binding protein (CREB) is influenced by melatonin treatment in pancreatic rat insulinoma $\beta$-cells (INS-1). Journal of Pineal Research 53 344-357. (doi:10.1111/j.1600-079X.2012.01004.x)

Bazwinsky-Wutschke I, Bieseke L, Mühlbauer E \& Peschke E 2014 Influence of melatonin receptor signalling on parameters involved in blood glucose regulation. Journal of Pineal Research 56 82-96. (doi:10.1111/jpi.12100)

Bedard K \& Krause KH 2007 The NOX family of ROS-generating NADPH oxidases: physiology and pathophysiology. Physiological Reviews $\mathbf{8 7}$ 245-313. (doi:10.1152/physrev.00044.2005)

Bulteau AL, Ikeda-Saito M \& Szweda LI 2003 Redox-dependent modulation of aconitase activity in intact mitochondria. Biochemistry 42 14846-14855. (doi:10.1021/bi0353979)

Dikalov S 2011 Cross talk between mitochondria and NADPH oxidases. Free Radical Biology and Medicine 51 1289-1301. (doi:10.1016/j. freeradbiomed.2011.06.033)

Dubocovich ML 1995 Melatonin receptors: are there multiple subtypes? Trends in Pharmacological Sciences 16 50-56. (doi:10.1016/S01656147(00)88978-6)

Ebelt H, Peschke D, Bromme HJ, Morke W, Blume R \& Peschke E 2000 Influence of melatonin on free radical-induced changes in rat pancreatic beta-cells in vitro. Journal of Pineal Research 28 65-72. (doi:10.1034/j.1600-079X.2001.280201.x)

Fisher SP \& Sugden D 2010 Endogenous melatonin is not obligatory for the regulation of the rat sleep-wake cycle. Sleep 33 833-840.

Graciano MF, Valle MM, Curi R \& Carpinelli AR 2013 Evidence for the involvement of GPR40 and NADPH oxidase in palmitic acid-induced superoxide production and insulin secretion. Islets 5 139-148. (doi:10.4161/isl.25459)

Hardeland R 2009 Melatonin: signaling mechanisms of a pleiotropic agent. Biofactors 35 183-192. (doi:10.1002/biof.23)

Hoffman RA \& Reiter RJ 1965 Rapid pinealectomy in hamsters and other small rodents. Anatomical Record 153 19-21. (doi:10.1002/ ar.1091530103)

Jaworek J, Zwirska-Korczala K, Szklarczyk J, Nawrot-Por囚bka K, LejaSzpak A, Jaworek AK \& Tomaszewska R 2010 Pinealectomy aggravates acute pancreatitis in the rat. Pharmacological Reports 62 864-873. (doi:10.1016/S1734-1140(10)70346-7)

Kahles T \& Brandes RP 2012 NADPH oxidases as therapeutic targets in ischemic stroke. Cellular and Molecular Life Science 69 2345-2363. (doi:10.1007/s00018-012-1011-8)

Lacy PE \& Kostianovsky M 1967 Method for the isolation of intact islets of Langerhans from the rat pancreas. Diabetes 16 35-39. (doi:10.2337/ diab.16.1.35)

Li N, Li B, Brun T, Deffert-Delbouille C, Mahiout Z, Daali Y, Ma XJ, Krause KH \& Maechler P 2012 NADPH oxidase NOX2 defines a new antagonistic role for reactive oxygen species and cAMP/PKA in the regulation of insulin secretion. Diabetes 61 2842-2850. (doi:10.2337/ db12-0009)

Lind C, Gerdes R, Schuppe-Koistinen I \& Cotgreave IA 1998 Studies on the mechanism of oxidative modification of human glyceraldehyde3-phosphate dehydrogenase by glutathione: catalysis by glutaredoxin. Biochemical and Biophysical Research Communications 247 481-486. (doi:10.1006/bbrc.1998.8695)

Livak KJ \& Schmittgen TD 2001 Analysis of relative gene expression data using real-time quantitative PCR and the 2(-Delta Delta C(T)) method. Methods 25 402-408. (doi:10.1006/meth.2001.1262)

Miyano K \& Sumimoto H 2007 Role of the small GTPase Rac in p22phoxdependent NADPH oxidases. Biochimie 89 1133-1144. (doi:10.1016/j. biochi.2007.05.003)

Morgan PJ, Barrett P, Hazlerigg D, Milligan G, Lawson W, MacLean A \& Davidson G 1995 Melatonin receptors couple through a cholera toxin-sensitive mechanism to inhibit cyclic AMP in the ovine pituitary. Journal of Neuroendocrinology 7 361-369. (doi:10.1111/j.1365-2826.1995.tb00770.x)

Morgan D, Rebelato E, Abdulkader F, Graciano MF, Oliveira-Emilio HR, Hirata AE, Rocha MS, Bordin S, Curi R \& Carpinelli AR 2009 Association of $\mathrm{NAD}(\mathrm{P}) \mathrm{H}$ oxidase with glucose-induced insulin secretion by pancreatic beta-cells. Endocrinology 150 2197-2201. (doi:10.1210/en.2008-1149)

Mühlbauer E \& Peschke E 2007 Evidence for the expression of both the MT1- and in addition, the MT2-melatonin receptor, in the rat pancreas, islet and beta-cell. Journal of Pineal Research 42 105-106. (doi:10.1111/j.1600-079x.2006.00399.x)

Munhoz AC, Riva P, Simões D, Curi R \& Carpinelli AR 2016 Control of insulin secretion by production of reactive oxygen species: study performed in pancreatic islets from fed and 48-hour fasted Wistar rats. PLOS ONE 11 e0158166. (doi:10.1371/journal.pone.0158166)

Nogueira TC, Lellis-Santos C, Jesus DS, Taneda M, Rodrigues SC, Amaral FG, Lopes AM, Cipolla-Neto J, Bordin S \& Anhê GF 2011 Absence of melatonin induces night-time hepatic insulin resistance and increased gluconeogenesis due to stimulation of nocturnal unfolded protein response. Endocrinology 152 1253-1263. (doi:10.1210/en.2010-1088)

Oliveira HR, Curi R \& Carpinelli AR 1999 Glucose induces an acute increase of superoxide dismutase activity in incubated rat pancreatic islets. American Journal of Physiology 276 C507-C510.

Peschke E \& Peschke D 1998 Evidence for a circadian rhythm of insulin release from perifused rat pancreatic islets. Diabetologia 41 1085-1092. (doi:10.1007/s001250051034)

Peschke E, Fauteck JD, Musshoff U, Schmidt F, Beckmann A \& Peschke D 2000 Evidence for a melatonin receptor within pancreatic islets http://joe.endocrinology-journals.org

DOI: $10.1530 / J O E-16-0259$
๑ 2016 Society for Endocrinology Printed in Great Britain 
of neonate rats: functional, autoradiographic, and molecular investigations. Journal of Pineal Research 28 156-164. (doi:10.1034/ j.1600-079X.2001.280305.x)

Picinato MC, Haber EP, Carpinelli AR \& Cipolla-Neto J 2002a Daily rhythm of glucose-induced insulin secretion by isolated islets from intact and pinealectomized rat. Journal of Pineal Research 33 172-177. (doi:10.1034/j.1600-079X.2002.02925.x)

Picinato MC, Haber EP, Cipolla-Neto J, Curi R, de Oliveira Carvalho CR \& Carpinelli AR 2002b Melatonin inhibits insulin secretion and decreases PKA levels without interfering with glucose metabolism in rat pancreatic islets. Journal of Pineal Research 33 156-160. (doi:10.1034/j.1600-079X.2002.02903.x)

Ramis MR, Esteban S, Miralles A, Tan DX \& Reiter RJ 2015 Protective effects of melatonin and mitochondria-targeted antioxidants against oxidative stress: a review. Current Medicinal Chemistry 22 2690-2711. (doi:10.2174/0929867322666150619104143)

Rebelato E, Abdulkader F, Curi R \& Carpinelli AR 2010 Low doses of hydrogen peroxide impair glucose-stimulated insulin secretion via inhibition of glucose metabolism and intracellular calcium oscillations. Metabolism 59 409-413. (doi:10.1016/j.metabol.2009.08.010)

Rebelato E, Abdulkader F, Curi R \& Carpinelli AR 2011 Control of the intracellular redox state by glucose participates in the insulin secretion mechanism. PLOS ONE 6 e24507. (doi:10.1371/journal. pone.0024507)

Rebelato E, Mares-Guia TR, Graciano MF, Labriola L, Britto LR, GarayMalpartida HM, Curi R, Sogayar MC \& Carpinelli AR 2012 Expression of $\mathrm{NAD}(\mathrm{P}) \mathrm{H}$ oxidase in human pancreatic islets. Life Science $\mathbf{9 1}$ 244-249. (doi:10.1016/j.lfs.2012.07.004)

Reiter RJ, Paredes SD, Korkmaz A, Manchester LC \& Tan DX 2008 Melatonin in relation to the "strong" and "weak" versions of the free radical theory of aging. Advances in Medical Sciences 53 119-129. (doi:10.2478/v10039-008-0032-x)

Stumpf I, Muhlbauer E \& Peschke E 2008 Involvement of the cGMP pathway in mediating the insulin-inhibitory effect of melatonin in pancreatic beta-cells. Journal of Pineal Research 45 318-327. (doi:10.1111/j.1600-079X.2008.00593.x)

Stumpf I, Bazwinsky I \& Peschke E 2009 Modulation of the cGMP signaling pathway by melatonin in pancreatic beta-cells. Journal of Pineal Research 46 140-147. (doi:10.1111/j.1600-079X.2008.00638.x)

Wind S, Beuerlein K, Eucker T, Müller H, Scheurer P, Armitage ME, Ho H, Schmidt HH \& Wingler K 2010 Comparative pharmacology of chemically distinct NADPH oxidase inhibitors. British Journal of Pharmacology 161 885-898. (doi:10.1111/j.1476-5381.2010.00920.x)

Wingler K, Hermans JJ, Schiffers P, Moens A, Paul M \& Schmidt HH 2011 NOX1, 2, 4, 5: counting out oxidative stress. British Journal of Pharmacology 164 866-883. (doi:10.1111/j.14765381.2011.01249.x)

Zhang HM \& Zhang Y 2014 Melatonin: a well-documented antioxidant with conditional pro-oxidant actions. Journal of Pineal Research $\mathbf{5 7}$ 131-146. (doi:10.1111/jpi.12162)

Zhao H, Kalivendi S, Zhang H, Joseph J, Nithipatikom K, Vasquez-Vivar J \& Kalyanaraman B 2003 Superoxide reacts with hydroethidine but forms a fluorescent product that is distinctly different from ethidium: potential implications in intracellular fluorescence detection of superoxide. Free Radical Biology and Medicine 34 1359-1368. (doi:10.1016/S0891-5849(03)00142-4)

Zhou J, Zhang S, Zhao X \& Wei T 2008 Melatonin impairs NADPH oxidase assembly and decreases superoxide anion production in microglia exposed to amyloid-beta1-42. Journal of Pineal Research 45 157-165. (doi:10.1111/j.1600-079X.2008.00570.x)

Received in final form 23 September 2016 Accepted 4 October 2016
๑) 2016 Society for Endocrinology Printed in Great Britain
Published by Bioscientifica Ltd. 